\title{
Categorization of Radioxenon
}

\author{
PE Keller
}

April 2012

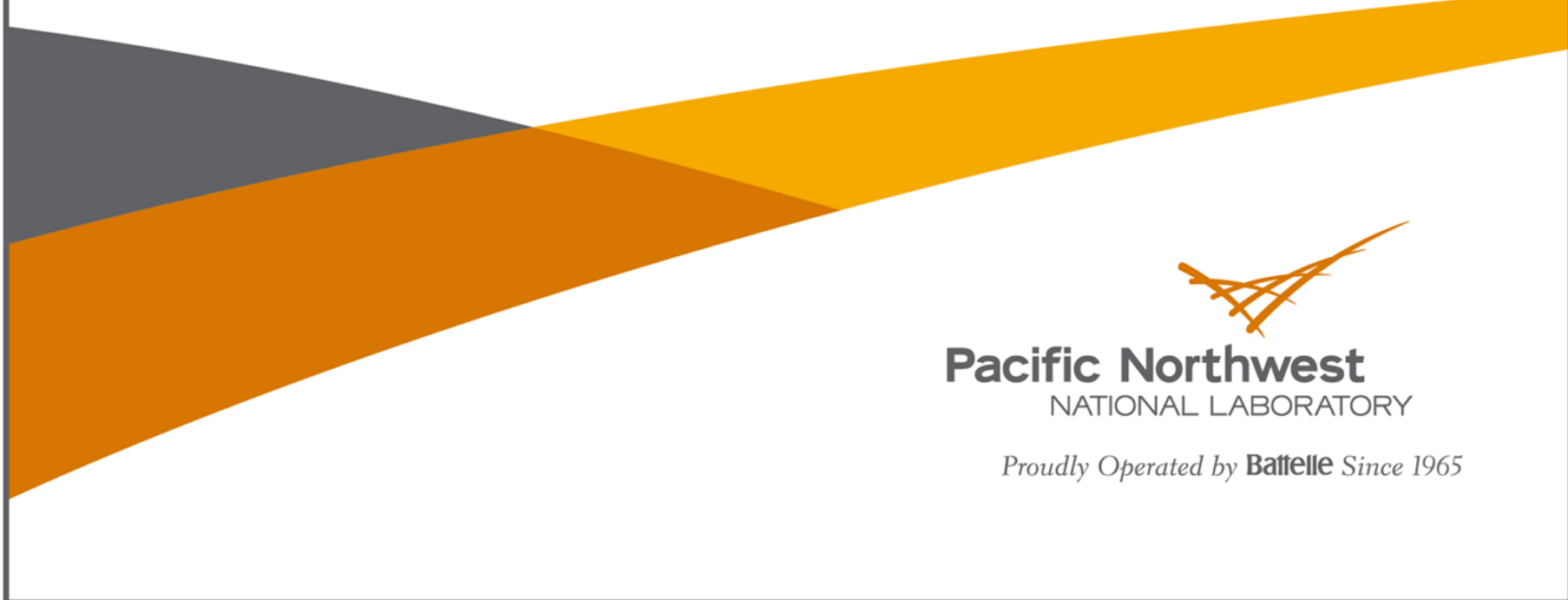




\title{
DISCLAIMER
}

This report was prepared as an account of work sponsored by an agency of the United States Government. Neither the United States Government nor any agency thereof, nor Battelle Memorial Institute, nor any of their employees, makes any warranty, express or implied, or assumes any legal liability or responsibility for the accuracy, completeness, or usefulness of any information, apparatus, product, or process disclosed, or represents that its use would not infringe privately owned rights. Reference herein to any specific commercial product, process, or service by trade name, trademark, manufacturer, or otherwise does not necessarily constitute or imply its endorsement, recommendation, or favoring by the United States Government or any agency thereof, or Battelle Memorial Institute. The views and opinions of authors expressed herein do not necessarily state or reflect those of the United States Government or any agency thereof.

\author{
PACIFIC NORTHWEST NATIONAL LABORATORY \\ operated by \\ BATTELLE \\ for the \\ UNITED STATES DEPARTMENT OF ENERGY \\ under Contract DE-AC05-76RL01830
}

Printed in the United States of America
Available to DOE and DOE contractors from the Office of Scientific and Technical Information,
P.O. Box 62, Oak Ridge, TN 37831-0062;
ph: (865) 576-8401
fax: $(865)$ 576-5728
email: reports@adonis.osti.gov

\begin{abstract}
Available to the public from the National Technical Information Service, U.S. Department of Commerce, 5285 Port Royal Rd., Springfield, VA 22161 ph: (800) 553-6847 fax: $(703) 605-6900$ email: orders@ntis.fedworld.gov online ordering: http://www.ntis.gov/ordering.htm
\end{abstract}

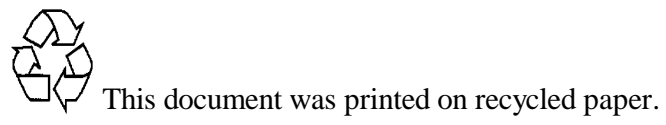


PNNL-21331

\section{Categorization of Radioxenon}

PE Keller

April 2012

Prepared for

the U.S. Department of Energy

under Contract DE-AC05-76RL01830

Pacific Northwest National Laboratory

Richland, Washington 99352 

PNNL-21331

\section{Executive Summary}

This report summarizes a study into some false positive issues in the use of radioxenon as a method to verify a clandestine nuclear weapons explosion. False positives arise due to similarities between the radioxenon signature generated in medical isotope production and that generated in a nuclear weapon explosion. This report also discusses how to categorize the radioxenon by levels of urgency for manual analysis and interpretation and recommends applying machine learning and time series analysis techniques in the automation of radioxenon characterization. The literature indicates that medical isotope production is a major contributor to atmospheric radioxenon and is the main source of confusion in determining the source of radioxenon. While radioxenon emissions from nuclear power plants can be distinguished from that from nuclear weapon explosions, emissions from medical isotope production generate signatures similar to certain nuclide ratios found in nuclear weapons explosions. Different techniques for analyzing nuclide concentrations and ratios as well as including other sensing modalities via sensor fusion are discussed. 



\section{Acronyms and Abbreviations}

$\begin{array}{ll}\text { ATM } & \text { Atmospheric Transport Modeling } \\ \text { CTBT } & \text { Comprehensive Test Ban Treaty } \\ \text { CTBTO } & \text { Comprehensive Test Ban Treaty Organization } \\ \text { HFR } & \text { High-Flux Reactor } \\ \text { HEU } & \text { Highly Enriched Uranium } \\ \text { IRE } & \text { Institut des Radioéléments } \\ \text { IMS } & \text { International Monitoring System } \\ \text { INGE } & \text { International Noble Gas Experiment } \\ \text { IPF } & \text { Isotope Production Facility } \\ \text { LEU } & \text { Low-Enriched Uranium } \\ \text { MDD } & \text { Maximum Detectable Distance } \\ \text { MIPF } & \text { Medical Isotope Production Facility } \\ \text { MDC } & \text { Minimum Detectable Concentration } \\ \text { MIRC } & \text { Multiple-Isotopic Ratio Correlation } \\ \text { NRU } & \text { National Research Universal } \\ \text { NG } & \text { Noble Gas } \\ \text { NPP } & \text { Nuclear Power Plant } \\ \text { Nuclear Weapons Explosion } \\ \text { Radiopharmaceutical Facilities }\end{array}$





\section{Contents}

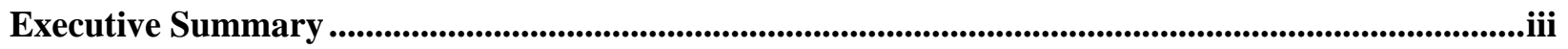

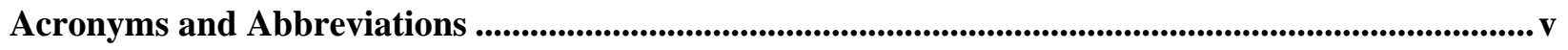

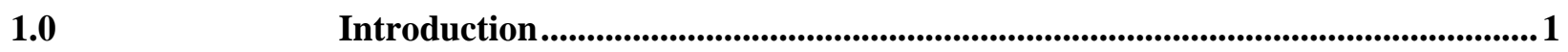

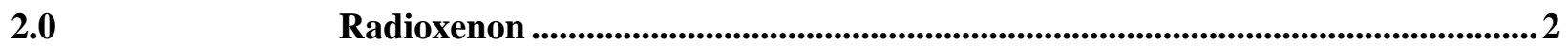

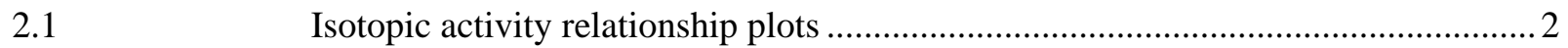

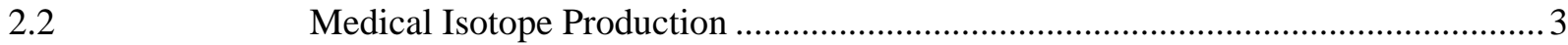

3.0 Proposed Methods for Dealing with Medical Isotope Production .......................5

Data Analysis Approach with Existing Data...........................................................5

3.2 Sensor Fusion with other Detection/Sensing Modalities .......................................5

Inclusion of Atmospheric Transport Modeling .................................................. 7

3.4 Modify procedures in Medical Isotope Production ................................................. 7

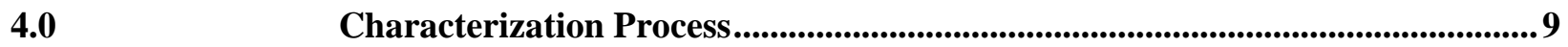

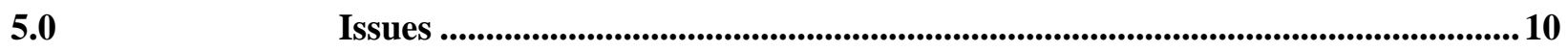

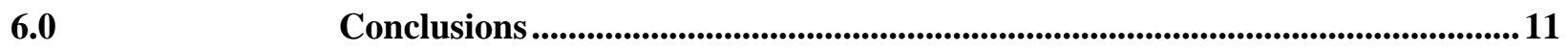

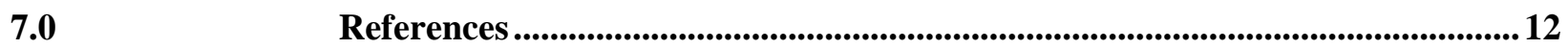

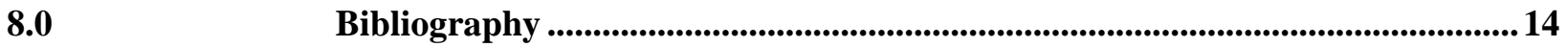


PNNL-21331

\section{Figures}

Figure 1. Regions in the MIRC plot for the four Nuclides of Radioxenon used in the CTBTO indicating source types as either Nuclear Power Plants or Nuclear Explosions ..........................3

Figure 2. General region of radioxenon ratios in the MIRC plot from MIPFs ..............................

Figure 3. Location of existing and future monitoring stations in the IMS ..................................6

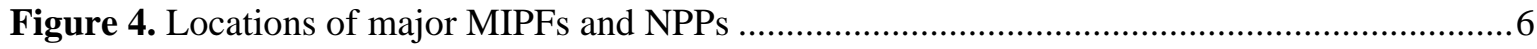

Figure 5. Venn diagram of the complementary and redundant information generated by multiple

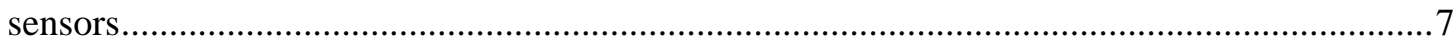


PNNL-21331

\section{Tables}

Table 1. Half-Lives of Radioxenon Nuclides Measured Under CTBT ...........................................2

Table 2. Activity of radioxenon emission from the major MIPFs …..........................................

Table 3. One Potential Characterization Level Scheme ............................................................ 



\subsection{Introduction}

The Comprehensive Test Ban Treaty Organization (CTBTO) is building a worldwide network of noble gas monitors as part of an effort to check compliance with the Comprehensive Test Ban Treaty (CTBT). This network is part of the International Monitoring System (IMS) and the instruments in the noble gas portion of the network collect and analyze air samples to determine the activities of four radioxenon nuclides $\left({ }^{131 \mathrm{~m}} \mathrm{Xe},{ }^{133 \mathrm{~m}} \mathrm{Xe},{ }^{133} \mathrm{Xe},{ }^{135} \mathrm{Xe}\right)$. The relative concentrations of these four nuclides can assist analysts in determining whether their source is nuclear power plants (NPPs) or a nuclear weapon explosion (NWE). For example, the ratio of ${ }^{135} \mathrm{Xe}$ to ${ }^{133} \mathrm{Xe}$ released by an NWE is orders of magnitude larger for an NWE than that released by an NPP.

Medical isotope production facilities (MIPFs) are another major source of radioxenon. While radioxenon from NWEs can be separated from radioxenon generated from NPPs by analyzing these ratios when levels are detectable, radioxenon from MIPFs is not as easily discriminated from NWEs. A literature search performed on the subject of radioxenon detection suggests that the prevalent view in the CTBT is that medical isotope production can confound analysis techniques that use the four radioxenon nuclides activity to discriminate an NWE from non-weapon sources of radioxenon.

The goal of characterizing radioxenon is to help clarify whether it is coming from an NWE or not. The result of the characterization should be an indication of how interesting a measurement or set of measurements is for this goal and indicate how urgently it needs to be manually analyzed. Overall, the radioxenon characterization product must definitively say "we found something of interest" when there is a reasonable possibility of an NWE. 


\subsection{Radioxenon}

Noble gas monitoring and radionuclide particulate monitoring are the only techniques that can potentially provide proof of whether an explosion was nuclear or not (De Geer 2011; Schulze et al. 2000). Radioxenon generally does not interact with soils and should escape from any underground test through normal cracks and fissures in the soil. For the atmospheric monitoring in CTBT, four nuclides of radioxenon $\left({ }^{131 \mathrm{~m}} \mathrm{Xe},{ }^{133 \mathrm{~m}} \mathrm{Xe},{ }^{133} \mathrm{Xe},{ }^{135} \mathrm{Xe}\right)$ were chosen for two reasons. First, they are fission products of both ${ }^{235} \mathrm{U}$ and ${ }^{239} \mathrm{Pu}$. Second, they have long enough half-lives for verification purposes, as shown in Table 1.

Table 1. Half-Lives of Radioxenon Nuclides Measured Under CTBT

\begin{tabular}{|l|l|}
\hline Nuclide & Half Life \\
\hline${ }^{131 \mathrm{~m}} \mathrm{Xe}$ & 11.84 days \\
\hline${ }^{133 \mathrm{~m}} \mathrm{Xe}$ & 2.19 days \\
\hline${ }^{133} \mathrm{Xe}$ & 5.243 days \\
\hline${ }^{135} \mathrm{Xe}$ & 9.14 hours \\
\hline
\end{tabular}

\subsection{Isotopic activity relationship plots}

To discriminate between different sources of radioxenon, nuclide ratios can be plotted against each other. Multiple-Isotopic Ratio Correlation (MIRC) plots the ratio of the activities of ${ }^{133 \mathrm{~m}} \mathrm{Xe}$ to ${ }^{131 \mathrm{~m}} \mathrm{Xe}$ versus the ratio of the activities of ${ }^{135} \mathrm{Xe}$ to ${ }^{133} \mathrm{Xe}$ (Kalinowski et al. 2010). Figure 1 illustrates how radioxenon from NPPs is discriminated from that produced by NWEs through the use of the MIRC plot. A comparison of the radioxenon nuclide ratios from NPPs will show a marked difference from those of NWEs and can be separated by a linear discriminator (i.e., line). This, however, assumes that the four nuclides are at or above the minimum detectable concentration (MDC), which is often not the case. 


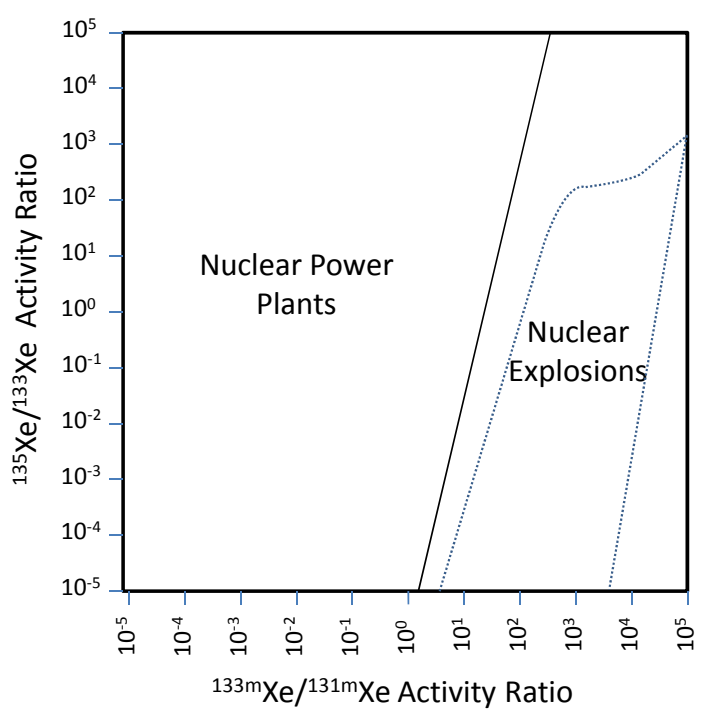

Figure 1. Regions in the MIRC plot for the four Nuclides of Radioxenon used in the CTBTO indicating source types as either Nuclear Power Plants or Nuclear Explosions

To overcome the challenges posed by a lack of detectable ${ }^{131 \mathrm{~m}} \mathrm{Xe}$, this report recommends analysts not rely on the four isotope MIRC plot alone, but also work with other activity ratio plots that do not include ${ }^{131 \mathrm{~m}} \mathrm{Xe}$. Other ratio plots can be generated using ${ }^{133 \mathrm{~m}} \mathrm{Xe} /{ }^{133} \mathrm{Xe},{ }^{135} \mathrm{Xe} /{ }^{133} \mathrm{Xe}$, and ${ }^{135} \mathrm{Xe} /{ }^{133 \mathrm{~m}} \mathrm{Xe}$. Also, plots of nuclide concentrations-versus-time and nuclide ratios-versus-time are important in radioxenon characterization (Heimbigner et al. 2002).

\subsection{Medical Isotope Production}

MIPFs taken as a whole are the most prolific non-weapons emitter of radioxenon, and thus the largest contributor to the background observed by monitoring stations deployed under the CTBT (Saey et al. 2010a). Three major MIPFs exist in the northern hemisphere: National Research Universal (NRU) at Chalk River, Canada; Institut des Radioéléments (IRE) at Fleurus, Belgium; and the High Flux Reactor (HFR) at Petten, The Netherlands. In the southern hemisphere, the highest radioxenon emitting MIPF is operated by NTP Radioisotopes in Pelindaba, South Africa. The radioxenon emissions from these four MIPFs are given in Table 2. NRU and HFR produce about one-third each of the world's supply of radiopharmaceuticals. HFR uses an alkaline process for dissolving the uranium targets instead of an acid process, which produces much less radioxenon than the NRU (Saey et al. 2010b; Sameh and Ache 1987).

Table 2. Activity of radioxenon emission from the major MIPFs

\begin{tabular}{|l|l|l|}
\hline Medical Isotope Production Facility & Location & Activity (Bq) \\
\hline National Research Universal (NRU) & Chalk River, Canada & $2 \times 10^{13}$ \\
\hline NTP Radioisotopes & Pelindaba, South Africa & $1.3 \times 10^{13}$ \\
\hline Institut des Radioéléments (IRE) & Fleurus, Belgium & $5 \times 10^{12}$ \\
\hline High Flux Reactor (HFR) & Petten, The Netherlands & $5 \times 10^{9}$ \\
\hline
\end{tabular}


Radioxenon commonly comes from the production of ${ }^{99} \mathrm{Mo}$, which is generally produced through fission of ${ }^{235} \mathrm{U}$ (Grosch 2008; Matthews et al. 2010). Molybdenum-99 is used to produce ${ }^{99 \mathrm{~m}} \mathrm{Tc}$ for use in a wide variety of medical diagnostic procedures. Radioxenon also comes from the production of ${ }^{131} \mathrm{I}$, which is used in gamma imaging systems, in the treatment of thyroid diseases, and to diagnose and treat inoperable childhood cancers. Xenon-133 itself is a radiopharmaceutical used in the gamma imaging of the heart, lungs, and brain via SPECT, and also is used to measure blood flow (perfusion) (Ross et al. 1964;

Tweddel and Martin 1992).

When uranium targets are used in the production of these isotopes, the radioxenon emissions from MIPFs have similar nuclide activity ratios to those produced by NWEs, resulting in difficulty discerning the likely source. Figure 2 highlights the region on a MIRC plot where nuclide ratios from MIPFs are found.

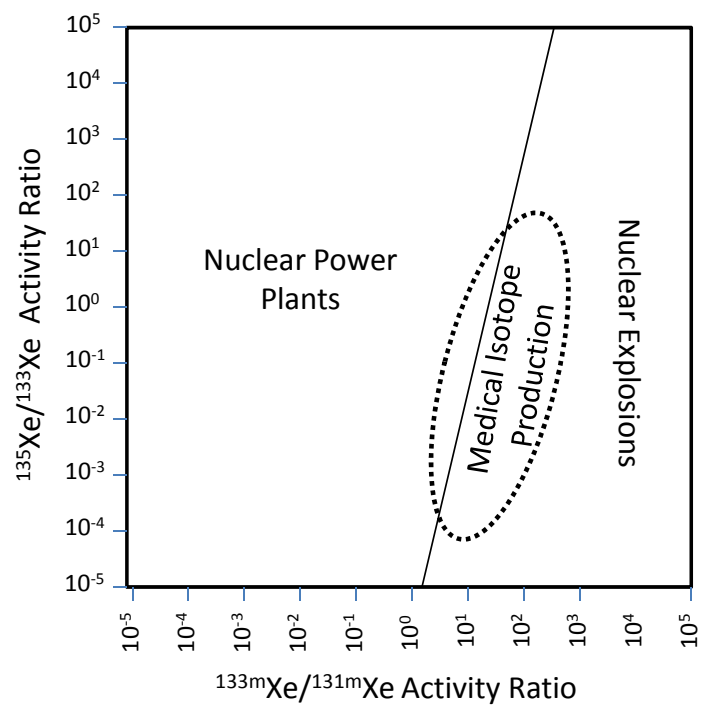

Figure 2. General region of radioxenon ratios in the MIRC plot from MIPFs

During the temporary suspension of production at the three major northern hemisphere MIPFs (from mid2008 until early 2009), analysis showed that MIPFs contributed fifteen times more radioxenon to the atmospheric background than did NPPs (Saey et al. 2010a; Ungar et al. 2009; Hoffman et al. 2009). During that period, measured values of ${ }^{133} \mathrm{Xe}$ dropped from 4.5 down to $1.1 \mathrm{mBq} / \mathrm{m}^{3}$ in Freiburg, Germany; and from 2.0 to $1.05 \mathrm{mBq} / \mathrm{m}^{3}$ in Stockholm, Sweden. These observations resulted in the conclusion that MIPFs are major contributors to the radioxenon background and that the global background is dominated by releases from MIPFs (Ringbom 2011).

Also, according to these observations the maximum detection distance (MDD) was estimated to be about $200 \mathrm{~km}$ for NPPs and $7800 \mathrm{~km}$ for MIPFs. This was the determined by finding the distance from the MIPFs at which the ${ }^{133} \mathrm{Xe}$ concentration dropped below $0.3 \mathrm{mBq} / \mathrm{m}^{3}$. This indicates that the output from just a few MIPFs in the world should be detectable over the whole IMS network. 


\subsection{Proposed Methods for Dealing with Medical Isotope Production}

Several approaches have been proposed for overcoming the challenges of obtaining accurate detection of potential NWEs with the obfuscation of measurements caused by medical isotope production.

\subsection{Data Analysis Approach with Existing Data}

Several data analysis techniques can be useful in mitigating confusion between an NWE and non-weapon sources. These techniques include time-series analysis, statistical analysis, and machine learning.

The decay process of the different isotopes as determined by time-series analysis, is an important factor in determining its source of origin (Kalinowski 2011). There have been some reports of time-series analysis of radioxenon succeeding in discriminating between NWEs and non-weapon sources. Plastino et al. (2010) performed a study on event classification by using time series radioxenon data detrended with the associated weather phenomenon. With time-series analysis, it is critical to know the amount of time necessary to predict the source type so that a determination can be made in a timely manner in order to respond to the event.

Another, statistical approach uses Bayesian decision methods, which enable inference of the likely source based on prior probabilities of the nuclide ratios (Zähringer and Kirchner 2008). In nuclide ratio analysis, Bayes statistics has an advantage over conventional statistics in that it allows all available prior (a priori) information to be used in the decision process, producing a more robust result.

Machine learning has been applied to simulations of radioxenon sources. Stocki et al. (2010) reported on the application of "naive Bayes," multilayer perceptron neural networks, decision trees, k-nearest neighbors, and support vector machines that were all trained and tested with simulated activity concentrations of the four nuclides measured in IMS. These machine learning techniques were found to outperform simple linear discriminators in high-radioxenon backgrounds. Further work would be necessary to show their ability to discriminate MIPFs from NWEs and to handle cases where ${ }^{131 \mathrm{~m}}$ Xe was below MDC and thus not available for analysis.

\subsection{Sensor Fusion with other Detection/Sensing Modalities}

A basic sensor fusion approach would simply involve combining the findings of the radioxenon detection system, whereas a full sensor fusion approach would include other sensing modalities in CTBTO's IMS. The IMS consists of four parts covering multiple sensor modalities: seismic, hydroacoustic, infrasound, and radionuclides (both particulate and noble gases). Stations in the system are distributed all over the world. Figure 3 plots the locations of the different sensor networks that make up the IMS.

Sensor fusion exploits complementary phenomenology from each detection or sensing modality to produce more useful information than any single modality can provide individually, as diagrammed in Figure 5. The improved results of this technique derive from both the complementary information unique to each modality and the redundant information common to many or all modalities. While the complementary data increases the information content, the redundant data can be used to reduce artifacts 
or inconsistencies introduced by the sensor fusion process to reduce false positives while concurrently improving discrimination accuracy.

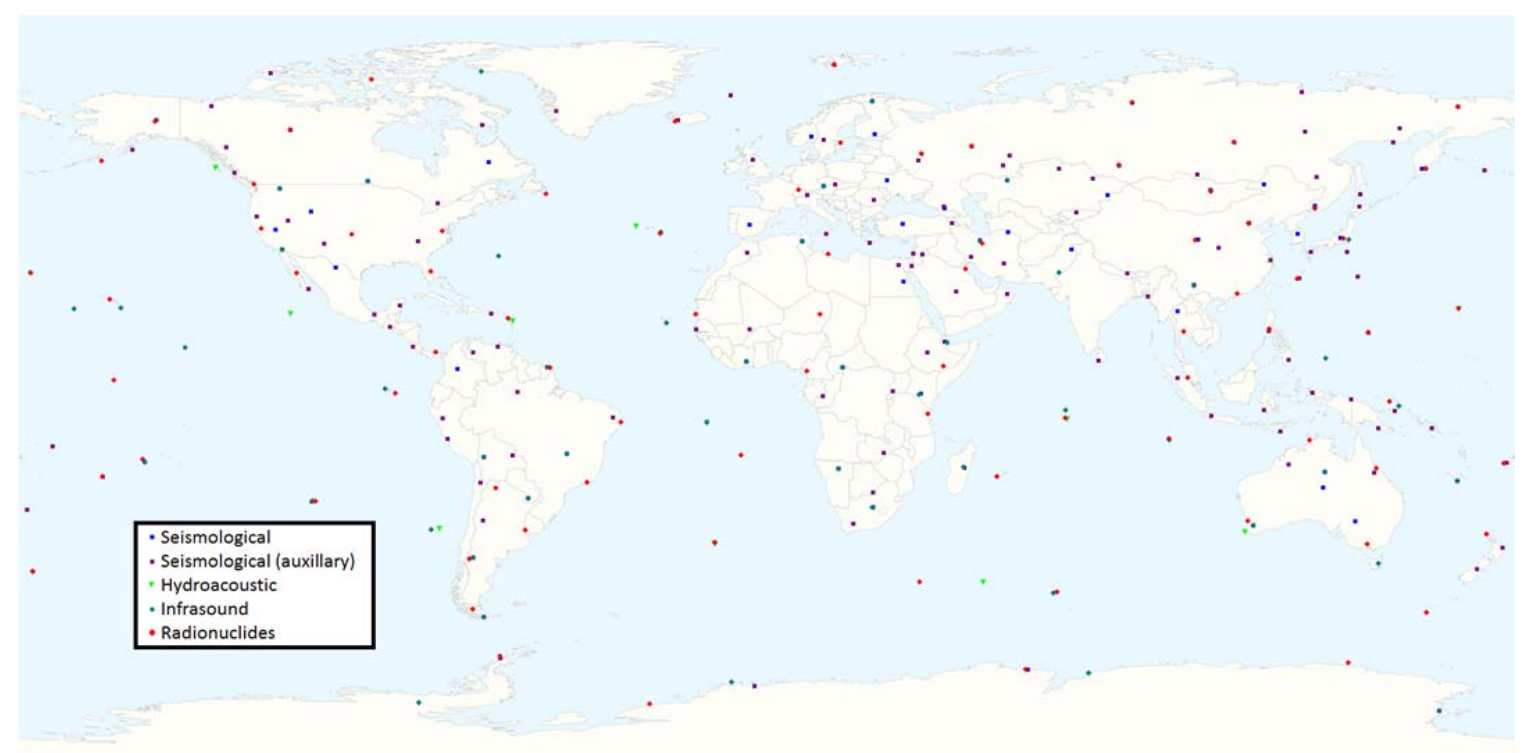

Figure 3. Location of existing and future monitoring stations in the IMS

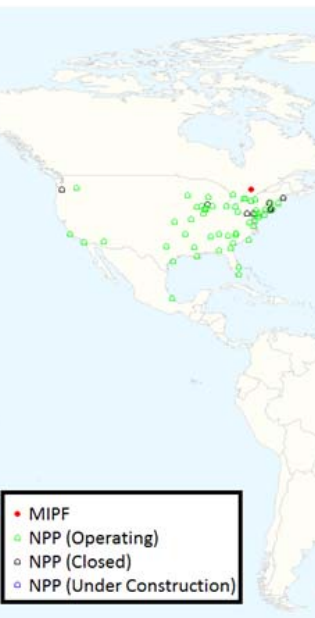

Figure 4. Locations of major MIPFs and NPPs

Many techniques have been used for sensor fusion, including weighted averages, wavelets, graph pyramids, neural networks, rule-based systems, fuzzy logic, hidden Markov models (when temporal signals are involved), and principal components analysis to name a few. 
PNNL-21331

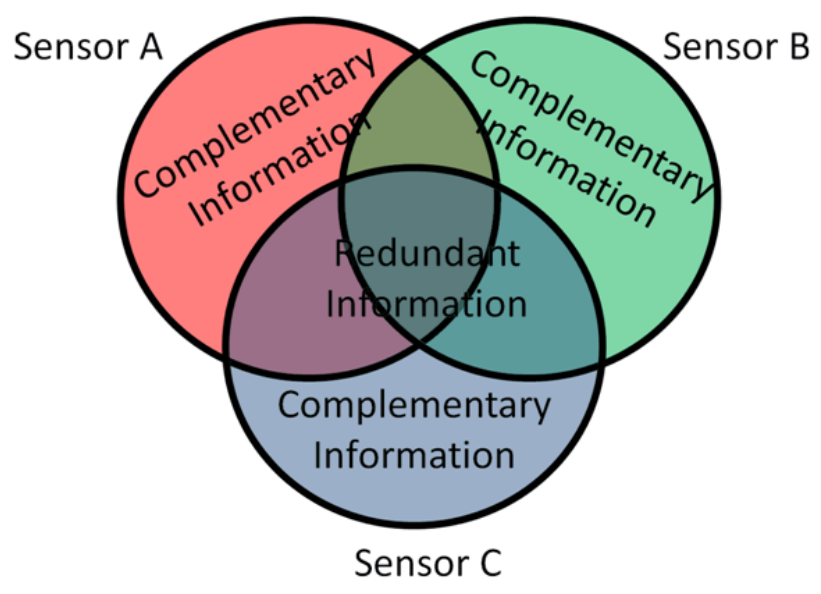

Figure 5. Venn diagram of the complementary and redundant information generated by multiple sensors

\subsection{Inclusion of Atmospheric Transport Modeling}

Atmospheric transport modeling (ATM) would provide modeled information about the probabilities that detected radioxenon was coming from known sources such as NPPs and MIPFs. The ATM would need to include information about all known sources and their locations, as well as current weather information.

One proposed ATM approach would start by flagging a suspicious signature, and then backtrack to known sources (Schöppner et al. 2011). Next, it would estimate the contributions from known sources to the nearby IMS stations. The contributions of the known sources would then be subtracted from the signals recorded at the nearby IMS stations and fed into an analysis method that would grade the signal with a level indicating the urgency of manual interpretation of the detected signal.

The ATM approach was discussed, but an issue that Dr. Steven Biegalski of the University of Texas at Austin brought up is that a database containing only the unclassified known sources around the world would still result in a classified data base, resulting in the necessity of running the ATM in a classified environment.

\subsection{Modify procedures in Medical Isotope Production}

A fourth option is to modify the medical isotope production process to reduce radioxenon emission from MIPFs.

A one method for doing this is to hold target material longer at the MIPF before using it for production, to allow most of the radioxenon to decay_into a stable daughter nuclide. Biegalski showed through simulation that using accumulation tanks to hold irradiated targets would change the radioxenon activity ratios enough to make the isotopes discernible from an NWE (Biegalski et al. 2010). The added benefit of using accumulation tanks is that the activity of the emissions is also reduced. Another option is to add a tracer isotope to the MIPF process to uniquely mark it as a MIPF, though this would raise public concern about adding new emissions. Finally, the most expensive method of reducing radioxenon 
PNNL-21331

emission from MIPFs is to convert the target dissolution process from an acid based to an alkaline based. This is the process used at the High Flux Reactor in Petten, The Netherlands. 


\subsection{Characterization Process}

The first three categories discussed in the last section involve analysis of measured IMS data. The goal of the analysis is to indicate the level of likelihood that the measured radioxenon is from an NWE, how much manual interpretation is needed, and the urgency of this interpretation. This output would likely be a set of levels. For example, this range could be from 1 to 5, in which 1 indicates normal background and 5 would indicate that the likelihood of an NWE is great enough to necessitate an immediate manual analysis. Table 3 illustrates this possible set of characterizations with the appropriate responses. Another potential output would be a "traffic light," with levels 1 and 2 being green, 3 being yellow, and 4 and 5 being red.

Table 3. One Potential Characterization Level Scheme

\begin{tabular}{|c|l|l|}
\hline Level & Likely Scenario & Response \\
\hline 1 & Normal Background & None \\
\hline 2 & Above Background & None \\
\hline 3 & Likely Non-weapon Source & Daily review \\
\hline 4 & Possible Weapon Source & Manual analysis within a few hours \\
\hline 5 & Likely Weapon Source & Immediate manual analysis \\
\hline
\end{tabular}


PNNL-21331

\subsection{Issues}

The main issues in the characterization of radioxenon include

1. the similarity in the radioxenon emissions from MIPFs and NWEs,

2. a lack of measureable ${ }^{131 \mathrm{~m}} \mathrm{Xe}$ since its concentration can be below the MDC, and

3. the urgency in making a determination of the likelihood of an NWE. 
PNNL-21331

\subsection{Conclusions}

The ability to discriminate radioxenon emissions generated by a nuclear weapon explosion from those emitted by medical isotope productions is key. The most likely near-term solution would rely only on noble gas monitoring, specifically the four radioxenon nuclides used for analysis. Xenon- $131 \mathrm{~m}$ is often below the minimum detectable concentration, but analysis methods must be able to work even when ${ }^{131 \mathrm{~m}} \mathrm{Xe}$ is not available. The resulting radioxenon characterization system should produce a graded scale as to how significant or interesting the measured radioxenon is and the appropriate level of response.

This report recommends applying both machine-learning methods and time-series analysis of radioxenon activities and ratios. This report also recommends producing a graded level of characterization. A major requirement in performing this recommended study would be the ability to determine the time available to make an analysis and how uncertainties in the data affect the chosen categorization level and time to make the categorization. Ideally, the graded output level would include some indication of confidence in the level chosen.

Beyond these recommendations, this report recommends including sensor fusion with the other IMS sensor modalities. Such a fused analysis would likely produce a more robust distinction between xenon resulting from medical isotope production and that from nuclear weapon explosion. 
PNNL-21331

\subsection{References}

Biegalski, SR, T Saller, J Helfand, and KMF Biegalski. 2010. "Sensitivity Study on Modeling Radioxenon Signals from Radiopharmaceutical Production Facilities." Journal of Radioanalytical and Nuclear Chemistry 284(3):663-68. 10.1007/s10967-010-0533-5.

De Geer, L-E. 2011. Radioxenon Signatures from Underground Nuclear Explosions. Presented at CTBT Science and Technology 2011, CTBTO, Vienna, Austria.

Grosch, M. 2008. "Complications of the Medical Radioisotope Production for the Non-Proliferation Regime." University of Hamburg, Hamburg, Germany: Center for Science and Peace Research. Master of Peace and Security Policy Studies Master's Thesis.

Heimbigner, TR, JC Hayes, TW Bowyer, JI McIntyre, and ME Panisko. 2002. Environmental Monitoring of Radioxenon in Support of the Radionuclide Measurement System of the International Monitoring System. Presented at 24th Seismic Research Review - Nuclear Explosion Monitoring: Innovation and Integration, NNSA, Washington, DC.

Hoffman, I, K Ungar, M Bean, J Yi, R Servranckx, C Zaganescu, N Ek, X Blanchard, G Le Petit, G Brachet, P Achim, and T Taffary. 2009. "Changes in Radioxenon Observations in Canada and Europe During Medical Isotope Production Facility Shut Down in 2008." Journal of Radioanalytical and Nuclear Chemistry 282(3):767-72. 10.1007/s10967-009-0235-z.

Kalinowski, MB. 2011. Temporal Evolution of the Radioxenon Signature from Undeground Nuclear Explosions. Presented at CTBT Science and Technology 2011, CTBTO, Vienna, Austria.

Kalinowski, MB, A Axelsson, M Bean, X Blanchard, TW Bowyer, G Brachet, S Hebel, JI McIntyre, J Peters, C Pistner, M Raith, A Ringbom, PRJ Saey, C Schlosser, TJ Stocki, T Taffary, and RK Ungar. 2010. "Discrimination of Nuclear Explosions against Civilian Sources Based on Atmospheric Xenon Isotopic Activity Ratios." Pure and Applied Geophysics 167(4-5):517-39. 10.1007/s00024-009-0032-1.

Matthews, M, PRJ Saey, TW Bowyer, G Vandergrift, N Ramamoorthy, C Cutler, B Ponsard, R Mikolajczak, Y Tsipenyuk, L Solin, D Fisher, G Dolinar, R Higgy, I Schraick, E Carranza, S Biegalski, B Deconninck, A Ringbom, A Sameh, D Amaya, E Hoffman, L Barbosa, J Camps, E Duran, M Zaehringer, A Rao, J Turinetti, D Mercer, M Auer, P Achim, V Popov, G Steinhauser, S Hebel, A Becker, and S Solomon. 2010. Workshop on Signatures of Medical and Industrial Isotope Production-a Review. Report No. PNNL-19294, Pacific Northwest National Laboratory, Richland, WA.

Plastino, W, R Plenteda, G Azzari, A Becker, PRJ Saey, and G Wotawa. 2010. "Radioxenon Time Series and Meteorological Pattern Analysis for CTBT Event Categorisation." Pure and Applied Geophysics 167(4-5):559-73. 10.1007/s00024-009-0030-3.

Ringbom, A. 2011. The Global Radioxenon Background - and Its Impact on Nuclear Explosion Monitoring. Presented at CTBT Science and Technology 2011, CTBTO, Vienna, Austria.

Ross, RS, PR Lichtlen, JR Rees, and K Ueda. 1964. "Measurement of Myocardial Blood Flow in Animals + Man by Selective Injection of Radioactive Inert Gas into Coronary Arteries." Circulation Research 15(1):28-\&. 
Saey, PRJ, M Auer, A Becker, E Hoffmann, M Nikkinen, A Ringbom, R Tinker, C Schlosser, and M Sonck. 2010a. "The Influence on the Radioxenon Background During the Temporary Suspension of Operations of Three Major Medical Isotope Production Facilities in the Northern Hemisphere and During the Start-up of Another Facility in the Southern Hemisphere." Journal of Environmental Radioactivity 101(9):730-38. 10.1016/j.jenvrad.2010.04.016.

Saey, PRJ, TW Bowyer, and A Ringbom. 2010b. "Isotopic Noble Gas Signatures Released from Medical Isotope Production Facilities-Simulations and Measurements." Applied Radiation and Isotopes 68(9):1846-54. 10.1016/j.apradiso.2010.04.014.

Sameh, A, and H Ache. 1987. "Production Techniques of Fission Molybdenum-99." Radiochimica Acta 41(1987):65-72.

Schöppner, M, MB Kalinowski, and W Plastino. 2011. Atmospheric Transport Modeling and Radioxenon Analysis Methods to Distinguish Civilian from Nuclear Explosion Signals. Presented at CTBT Science and Technology 2011, CTBTO, Vienna, Austria.

Schulze, J, M Auer, and R Werzi. 2000. "Low Level Radioactivity Measurement in Support of the CTBTO." Applied Radiation and Isotopes 53(1-2):23-30. 10.1016/s0969-8043(00)00182-2.

Stocki, TJ, GC Li, N Japkowicz, and RK Ungar. 2010. "Machine Learning for Radioxenon Event Classification for the Comprehensive Nuclear-Test-Ban Treaty." Journal of Environmental Radioactivity 101(1):68-74. 10.1016/j.jenvrad.2009.08.015.

Tweddel, A, and W Martin. 1992. "Myocardial Perfusion Imaging with Xenon-133." In What's New in Cardiac Imaging?, eds. HSEVD Wall, A Righetti and MG Niemeyer, pp. 41-48. Kluwer Academic Publishers, Dordrecht, The Netherlands.

Ungar, K, M Bean, J Yi, I Hoffman, R Servranckx, C Zaganescu, N Ek, X Blanchard, G Le Petit, G Brachet, P Achim, and T Taffary. 2009. Changes in Radioxenon Observations in Canada and Europe During Medical Isotope Production Facility Shut Downs in 2008. Presented at CTBT International Scientific Studies Conference, CTBTO, Vienna, Austria.

Zähringer, M, and G Kirchner. 2008. "Nuclide Ratios and Source Identification from High-Resolution Gamma-Ray Spectra with Bayesian Decision Methods." Nuclear Instruments \& Methods in Physics Research Section a-Accelerators Spectrometers Detectors and Associated Equipment 594(3):400-06. 10.1016/j.nima.2008.06.044. 
PNNL-21331

\subsection{Bibliography}

Bass, HE, J Bhattacharyya, MA Garces, M Hedlin, JV Olson, and RL Woodward. 2006. "Infrasound." Acoustics Today 2(1):9-19.

Biegalski, S, MR Deinert, J Lowrey, and CR Perez. 2011. Radioxenon Signatures from Underground Transport and Radiopharmaceutical Facilities. Presented at 2011 Monitoring Research Review, $10 \mathrm{pp}$.

Biegalski, SR, T Saller, J Helfand, and KMF Biegalski. 2010. "Sensitivity Study on Modeling Radioxenon Signals from Radiopharmaceutical Production Facilities." Journal of Radioanalytical and Nuclear Chemistry 284(3):663-68. 10.1007/s10967-010-0533-5.

Bowyer, TW, C Schlosser, KH Abel, M Auer, JC Hayes, TR Heimbigner, JI McIntyre, ME Panisko, PL Reeder, H Satorius, J Schulze, and W Weiss. 2002. "Detection and Analysis of Xenon Isotopes for the Comprehensive Nuclear-Test-Ban Treaty International Monitoring System." Journal of Environmental Radioactivity 59(2):139-51. 10.1016/s0265-931x(01)00042-x.

De Geer, L-E. 2011. Radioxenon Signatures from Underground Nuclear Explosions. Presented at CTBT Science and Technology 2011, CTBTO, Vienna, Austria.

Fontaine, JP, F Pointurier, X Blanchard, and T Taffary. 2004. "Atmospheric Xenon Radioactive Isotope Monitoring." Journal of Environmental Radioactivity 72(1-2):129-35. 10.1016/s0265931x(03)00194-2.

Grosch, M. 2008. "Complications of the Medical Radioisotope Production for the Non-Proliferation Regime." University of Hamburg, Hamburg, Germany: Center for Science and Peace Research. Master of Peace and Security Policy Studies Master's Thesis.

Haas, D, B Schrom, M Cooper, J Ely, A Flory, J Hayes, T Heimbigner, J McIntyre, D Saunders, and T Suckow. 2010. "Progress in Advanced Spectral Analysis of Radioxenon." In 2010 Monitoring Research Review: Ground Based Nuclear Explosion Monitoring Technologies, pp. 604-08. Los Alamos National Laboratory, Los Alamos, NM.

Heimbigner, TR, TW Bowyer, JI McIntyre, KH Abel, JC Hayes, ME Panisko, and WK Pitts. 2000. The DOE Automated Radioxenon Sampler-Analyzer (ARSA) Beta-Gamma Coincidence Spectrometer Data Analyzer. Presented at 22nd Seismic Research Review NNSA, Washingon, DC.

Heimbigner, TR, JC Hayes, TW Bowyer, JI McIntyre, and ME Panisko. 2002. Environmental Monitoring of Radioxenon in Support of the Radionuclide Measurement System of the International Monitoring System. Presented at 24th Seismic Research Review - Nuclear Explosion Monitoring: Innovation and Integration, NNSA, Washington, DC.

Hippel, FNV, and LH Kahn. 2006. "Feasibility of Eliminating the Use of Highly Enriched Uranium in the Production of Medical Radioisotopes." Science \& Global Security 14(2-3):151-62.

10.1080/08929880600993071. 
Hoffman, I, K Ungar, M Bean, J Yi, R Servranckx, C Zaganescu, N Ek, X Blanchard, G Le Petit, G Brachet, P Achim, and T Taffary. 2009. "Changes in Radioxenon Observations in Canada and Europe During Medical Isotope Production Facility Shut Down in 2008." Journal of Radioanalytical and Nuclear Chemistry 282(3):767-72. 10.1007/s10967-009-0235-z.

Kalinowski, MB. 2011. Temporal Evolution of the Radioxenon Signature from Undeground Nuclear Explosions. Presented at CTBT Science and Technology 2011, CTBTO, Vienna, Austria.

Kalinowski, MB, A Axelsson, M Bean, X Blanchard, TW Bowyer, G Brachet, S Hebel, JI McIntyre, J Peters, C Pistner, M Raith, A Ringbom, PRJ Saey, C Schlosser, TJ Stocki, T Taffary, and RK Ungar. 2010. "Discrimination of Nuclear Explosions against Civilian Sources Based on Atmospheric Xenon Isotopic Activity Ratios." Pure and Applied Geophysics 167(4-5):517-39. 10.1007/s00024-009-0032-1.

Le Petit, G, P Armand, G Brachet, T Taffary, JP Fontaine, P Achim, X Blanchard, JC Piwowarczyk, and F Pointurier. 2008. "Contribution to the Development of Atmospheric Radioxenon Monitoring." Journal of Radioanalytical and Nuclear Chemistry 276(2):391-98. 10.1007/s10967-008-0517-x.

Matthews, M, PRJ Saey, TW Bowyer, G Vandergrift, N Ramamoorthy, C Cutler, B Ponsard, R Mikolajczak, Y Tsipenyuk, L Solin, D Fisher, G Dolinar, R Higgy, I Schraick, E Carranza, S Biegalski, B Deconninck, A Ringbom, A Sameh, D Amaya, E Hoffman, L Barbosa, J Camps, E Duran, M Zaehringer, A Rao, J Turinetti, D Mercer, M Auer, P Achim, V Popov, G Steinhauser, S Hebel, A Becker, and S Solomon. 2010. Workshop on Signatures of Medical and Industrial Isotope Production-a Review. Report No. PNNL-19294, Pacific Northwest National Laboratory, Richland, WA.

McIntyre, JI, TW Bowyer, and PL Reeder. 2006. Calculation of Minimum-Detectable-Concentration Levels of Radioxenon Isotopes Using the PNNL ARSA System. Report No. PNNL-13102, Pacific Northwest National Laboratory, Richland, WA.

Miley, H. 2011. Understanding the Radionuclide Source Term for Underground Nuclear Explosions. Presented at CTBT Science and Technology 2011, CTBTO, Vienna, Austria.

Plastino, W, R Plenteda, G Azzari, A Becker, PRJ Saey, and G Wotawa. 2010. "Radioxenon Time Series and Meteorological Pattern Analysis for CTBT Event Categorisation." Pure and Applied Geophysics 167(4-5):559-73. 10.1007/s00024-009-0030-3.

Ringbom, A. 2011. The Global Radioxenon Background - and Its Impact on Nuclear Explosion Monitoring. Presented at CTBT Science and Technology 2011, CTBTO, Vienna, Austria.

Ross, RS, PR Lichtlen, JR Rees, and K Ueda. 1964. "Measurement of Myocardial Blood Flow in Animals + Man by Selective Injection of Radioactive Inert Gas into Coronary Arteries." Circulation Research 15(1):28-41.

Schoeppner, M, M Kalinowski, W Plastino, and G Wotawa. 2011. Radioxenon Analysis Methods and Atmospheric Transport Modelling to Distinguish Civilian from Nuclear Explosion Signals. Presented at European Geosciences Union General Assembly, European Geosciences Union, Vienna, Austria. 
Schulze, J, M Auer, and R Werzi. 2000. "Low Level Radioactivity Measurement in Support of the CTBTO." Applied Radiation and Isotopes 53(1-2):23-30. 10.1016/s0969-8043(00)00182-2.

Stocki, TJ, X Blanchard, R D'Amours, RK Ungar, JP Fontaine, M Sohier, M Bean, T Taffary, J Racine, BL Tracy, G Brachet, M Jean, and D Meyerhof. 2005. "Automated Radioxenon Monitoring for the Comprehensive Nuclear-Test-Ban Treaty in Two Distinctive Locations: Ottawa and Tahiti." Journal of Environmental Radioactivity 80(3):305-26. 10.1016/j.jenvrad.2004.10.005.

Stocki, TJ, GC Li, N Japkowicz, and RK Ungar. 2010. "Machine Learning for Radioxenon Event Classification for the Comprehensive Nuclear-Test-Ban Treaty." Journal of Environmental Radioactivity 101(1):68-74. 10.1016/j.jenvrad.2009.08.015.

Tuma, M, and M Kalinowski. 2007. First Version of a Global Inventory of Radioxenon Emissions from Nuclear Power Plants. Presented at European Geosciences Union General Assembly 2007, European Geosciences Union, Vienna, Austria.

Tweddel, A, and W Martin. 1992. "Myocardial Perfusion Imaging with Xenon-133." In What's New in Cardiac Imaging?, eds. HSE Van Der Wall, A Righetti and MG Niemeyer, pp. 41-48. Kluwer Academic Publishers, Dordrecht, The Netherlands.

Ungar, K, M Bean, J Yi, I Hoffman, R Servranckx, C Zaganescu, N Ek, X Blanchard, G Le Petit, G Brachet, P Achim, and T Taffary. 2009. Changes in Radioxenon Observations in Canada and Europe During Medical Isotope Production Facility Shut Downs in 2008. Presented at CTBT International Scientific Studies Conference, CTBTO, Vienna, Austria.

Zähringer, M, and G Kirchner. 2008. "Nuclide Ratios and Source Identification from High-Resolution Gamma-Ray Spectra with Bayesian Decision Methods." Nuclear Instruments \& Methods in Physics Research Section a-Accelerators Spectrometers Detectors and Associated Equipment 594(3):400-06. 10.1016/j.nima.2008.06.044.

Zhang, W, K Ungar, I Hoffman, and R Lawrie. 2008. Noble Gas Inventories in the Primary Coolant of Nuclear Power Plant to Enhance Comprehensive Test Ban Treaty (CTBT) Verification. Presented at 10th International Conference on CANDU Fuel, CTBTO, Vienna, Austria.

Zhang, W, K Ungar, I Hoffman, and R Lawrie. 2009. "Xenon Isotopic Signature Study of the Primary Coolant of Candu Nuclear Power Plant to Enhance CTBT Verification." Journal of Radioanalytical and Nuclear Chemistry 280(1):121-28. 10.1007/s10967-009-7400-2. 



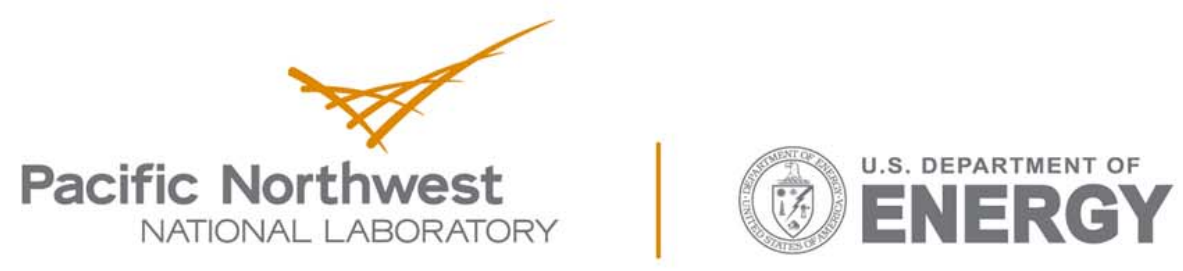

Proudly Operated by Battelle Since 1965

902 Battelle Boulevard

P.O. Box 999

Richland, WA 99352

1-888-375-PNNL (7665)

www.pnnl.gov 